\title{
Outside In/Inside Out: Extimacy and Public Space
}

\author{
NEREA FELIZ ARRIZABALAGA \\ University of Texas at Austin
}

\begin{abstract}
As the public sphere has intruded the privacy of the home, the semiotics of the domestic have migrated to workplaces and public squares. The entropic mixture of private and public environments is gradually altering the physiognomy of the city.
\end{abstract}

This article inquires about the complex dimensions that lie at the encounter between domestic and public territories. "Extimacy", the term coined by Jacques Lacan has been used in the context of critical psychology to reject the conventional distinction between psychological exteriority and interiority or intimacy. The word "Extimacy", points towards the intersection between two traditionally opposed states of the psyche, the outside and the inside, the exterior and the interior world of the mind ${ }^{1}$. I have chosen to borrow this term to describe how the progressive erasure of boundaries between the private and the public realm are increasingly affecting design practices and urban dynamics.

The last century has witnessed how the architectural distinction between inside and outside has slowly weakened. Today, working from home and growing accustomed to sharing personal data through a wide range of technology and social media, the established notions of public versus private are being profoundly challenged. On one hand technology facilitates the participation on public spheres from the privacy of home, while at the same time, we are experiencing an increased privatization and often interiorization of public space. Looking at contemporary environments and practices that are challenging the traditional association of interior with intimacy and exterior with public performance, this article attempts to reflect on the complex and multifaceted cross-fertilization among private domestic spaces and public urban places. The border crossing exchanges between the domestic, and the public environment, are generating a series of hybrid conditions that do not fully belong to either of these domains.

\section{THE SPATIAL CROSS-FERTILIZATION OF PUBLIC AND DOMESTIC FUNCTIONS}

Unparalleled population growth and capitalist forces on the urban real estate market are reducing the space available for dwelling and putting pressure on public urban space to operate as a domestic setting. Eating out, writing in cafes and showering at the gym, are very common practices in urban environments. The atomization of domestic functions across the city is most extreme in the form of the 'Bang' culture in Seoul. Due to the impact of the extended metropolis on commuting times, private activity, traditionally linked to the home environment, has exploded in fragments and is scattered throughout the city in remote, single-function locations. Bang, simply means room. In a traditional Korean house, a 'sarangbang' is the study or drawing room. In modern South Korea, the concept of a 'bang' has expanded from just being a dedicated room in a domestic space, to including public single-function rooms, such as the PC bang, a 'noraebang' (karaoke room), the 'sojubang' (private pub room), and the ‘jjimjilbang' (public bathhouse) ${ }^{2}$.

In parallel to the dispersion of the home, we can observe the progressive infiltration of public functions into the domestic space. 'IKEA Disobedients', the installation by Andres Jaque's Office for Political Innovation acquired by MoMA, reflects on the nature of contemporary dwelling as a semi-public hybrid activity, politically charged, and inseparable from local public life in the community. Andres Jaque's research in New York for the 'IKEA Disobedients' installation, identified households whose domestic reality belonged to this semi-public realm such as a home doubling as an aquaponics laboratory, an apartment which is periodically rented to host parties, or the transformation of a living room into a beauty salon. Andres Jaque explains how these case studies reflect the way in which domestic interiors are inter-connected to create social fabrics ${ }^{3}$. His research

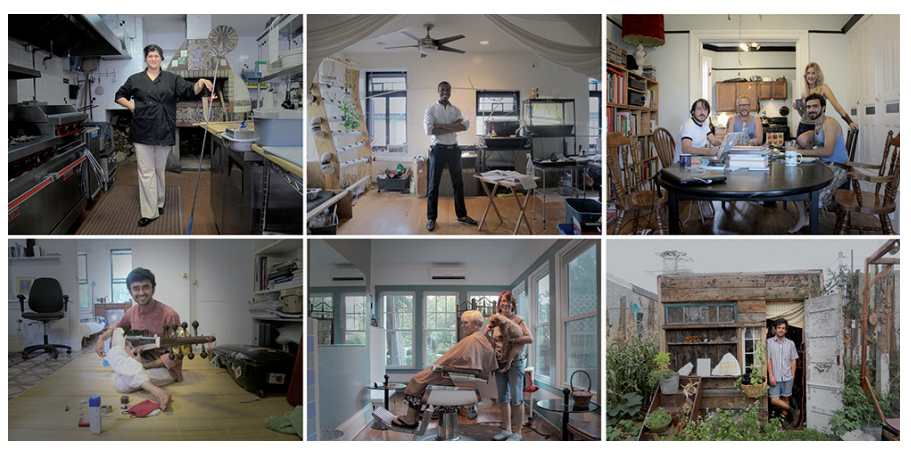

Figure 1: 'Portraits', IKEA Disobedients by Office for Political Innovation, 2011. Photos courtesy of Office for Political Innovation. 


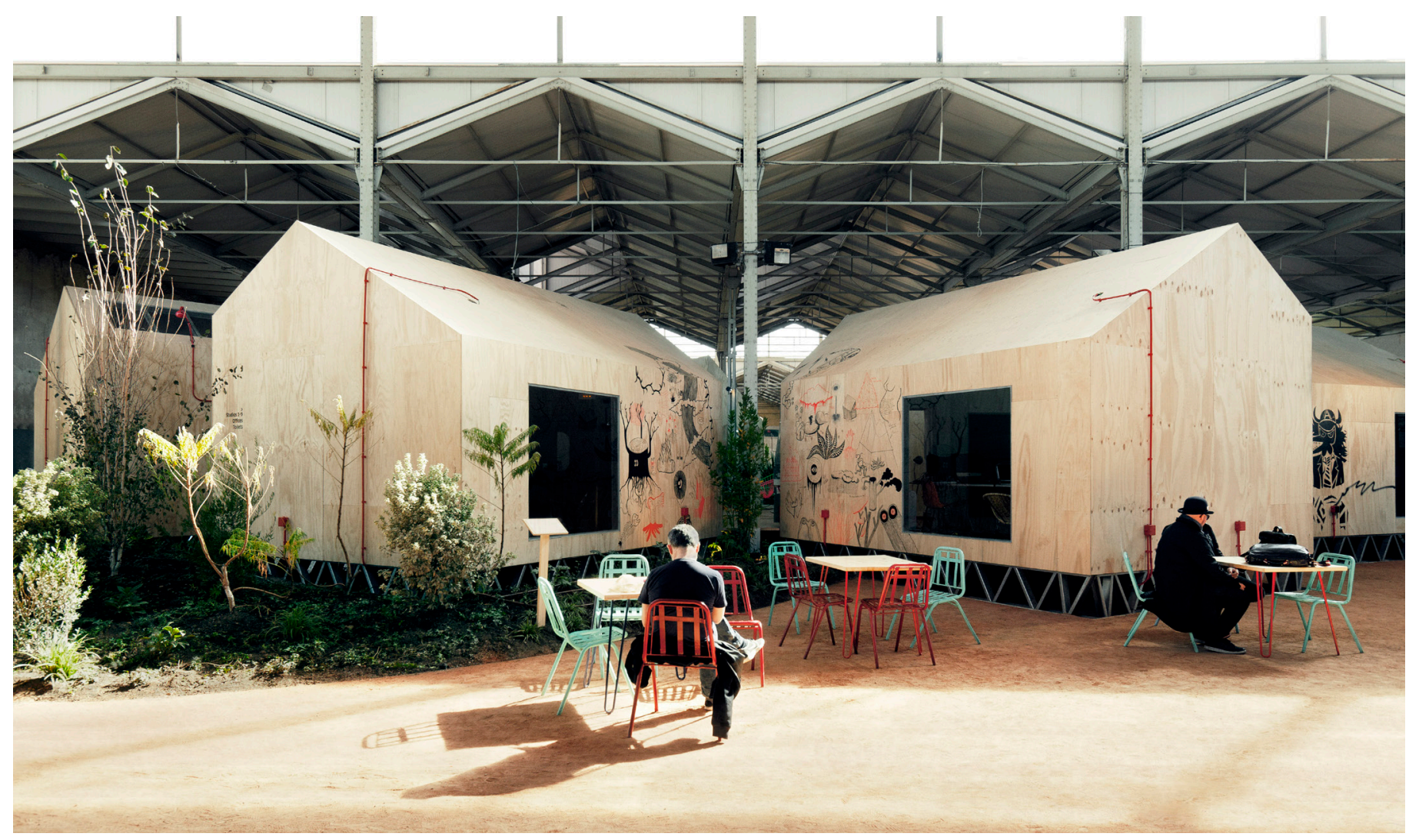

Figure 2: Red Bull Music academy headquarters by Langarita Navarro at Matadero, Madrid, 2011. Photo by Luis Diaz Diaz. Courtesy of Langarita Navarro.

produced a revealing catalogue of the public dimension of contemporary dwelling.

And while the domestic space of the dwelling takes on public functions, the semiotics of the domestic start to permeate other environments, gradually changing the physiognomy of the public sphere. Susan Yelavich describes how the 'home' is increasingly incarnated in multiple public settings, from shops to offices.

'It seems that the less time we spend at home the more we seek its comforts elsewhere'. ' 'Couches have migrated to bookstores, televisions populate doctor's offices, cushions double as library chairs and offices are sprouting small cottages and huts'. ${ }^{5}$

We are all familiar with the current trend to treat workplaces as relatively infantile domestic playgrounds initiated by Google. The tech giant's offices are being emulated worldwide in an attempt to reproduce the firm's home-like feel characterized by the famed 24 hours free snacks and an abundance of colorful sofas, ping pong tables and yurts. At the high end of this design tendency, Langarita Navarro Architectos' small cottages built in 2011 for the Red Bull Music Academy offices inside Nave 15 at Madrid's Matadero, reference the iconic volume of the home, generating a playful working environment. Composed of a field of house-like private working rooms within an interior garden-like setting, the worplace resembles a micro residential suburb. And even though the domestication of the public sphere can be perceived as a desirable quality due to its natural hospitality and welcoming nature, as Susan Yelavich points out, the coziness of the domestic can be used manipulatively. It may be argued that the infiltration of domestic semiotics and comforts into public spaces can help motivate its occupants into working longer hours, shopping extra and staying out longer, with the purpose of increasing productivity and consumption. ${ }^{6}$

\section{DOMESTICIY AND TACTICAL URBANISM}

Public space in the city has gradually changed from a truly public space to a conglomeration of multiple privately owned public spaces. Vito Acconci described this phenomena as one where the public is reconfigured "as a composite of privates" 7. As Public spaces progressively become privately controlled we find a lack of physical sites of unmediated social interaction. Pursuing the appropriation of urban space, a broad range of design projects have emerged in the form of tactical urbanism. These practices usually start by highlighting issues of neglect in order to provide public infrastructure that is missing. The creation of small nodes of socialization, urban identity and a sense of communal ownership of public urban space is often associated with the deployment of domestic settings. The appropriation of public space, both physically and programmatically, is frequently linked to its transformation into a temporary "collective domus". Constructing small scale ephemeral interventions, many of these practices tend to produce micro-utopias hosting traditionally domestic functions such as relaxing, reading, cooking, watching movies or lounging. The domestic commonly embodies the expression of the everyday, the quotidian. As design is gradually understood in the form of targeted provisional interventions tight to 


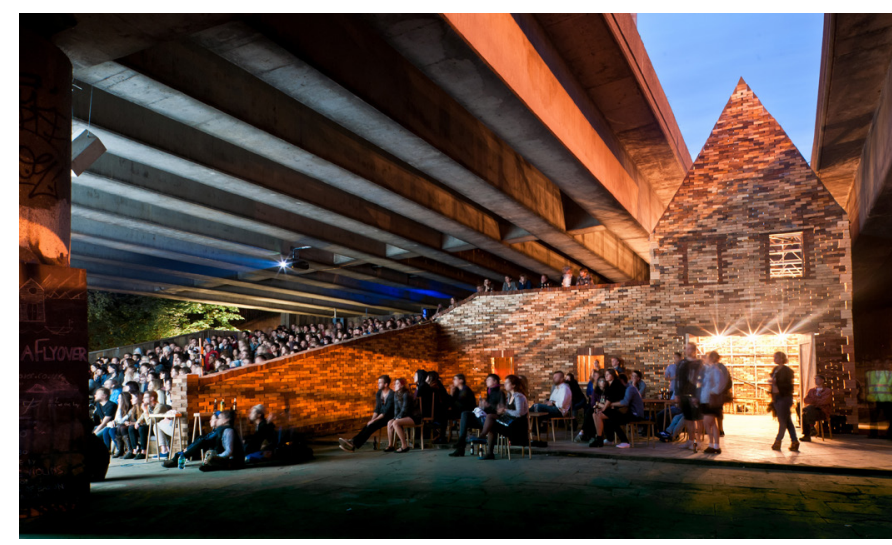

Figure 3: Folie for a Flyover by Assemble, Hackney Wick, East London, 2011 Courtesy of Assemble.

localized fluctuating conditions, everydayness and pragmatic specificity become key design values. From the multiple expressions of Parking day pop-up sites, to design awarded projects such as most of Assemble Studio completed projects or Interboro's 'Holding pattern' to name a few, one can speak of tactical urbanism design initiatives being related to the domestic in terms of scale, down-to earth functionalism, and even formal elements. The informal qualities associated to the household such as the familiar, relaxed, and personal climate of the home, when exported to the city, can enhance the participation of the public in the appropriation of urban space.

It could be argued that the search for spatial and aesthetic frameworks for heterogeneous forms of urban sociability are repeatedly associated with the interiorization and domestication of the city. Assemble's 'Folly for a Fly over' project, converted the unemployed underside of a highway into a performance art venue. Surprisingly this public space, took on the formal features of a traditional family house. Assemble explains their design choice as follows:

'Starting with the idea that how spaces are imagined is often as important as their physical characteristics in determining their use, the Folly reclaimed the future of the site by re-imagining its past. The new 'fairy tale' for the site described the Folly as the home of a stubborn landlord who refused to move to make way for the motorway, which was subsequently built around him, leaving him with his pitched roof stuck between the East and Westbound lanes.' ${ }^{8}$

I find this project to be a good example of how the adoption of the iconic figure of the house has been used to portray elements of user resistance and the desire to transform an unwelcoming site into a new homely and friendly environment.

Also by Assemble, the 2010 Cineroleum project, a self-initiated intervention transforming a petrol station in London's Clerkenwell Road into a temporary cinema, was an experiment in the potential for the wider re-use of 4,000 UK's empty petrol stations. ${ }^{9}$ Nonconformist, adaptive uses of public space can be manifested through the application of traditionally interior devices. In this case, a curtain, which

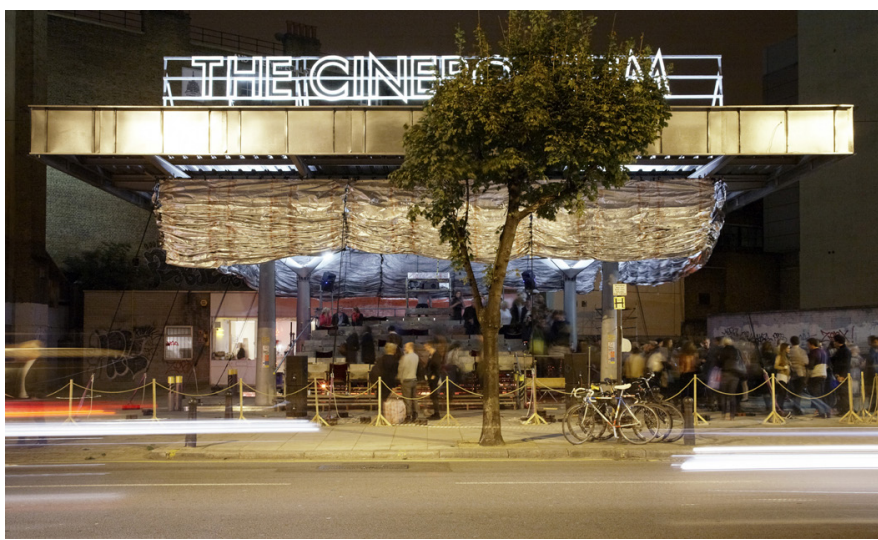

Figure 4: Cineroleum by Assemble, Albion Buildings, Clerkenwell Rd, London EC1R 5EN, UK, 2010. Courtesy of Assemble.

operates as a means to invite and welcome visitors to the performance space with a soft perimeter.

Interboro's winning proposal for MoMA's PS1 pavilion in 2011 consisted of a series of simple functional furnishings. Prior to the design, Interboro met with local institutions and asked them what items they needed in the community. In response to their findings, the office designed seventy-nine loose items to be held temporarily at the PS1 during the summer. When the installation was over, the objects including benches, patio furniture, chaise lounges, ping pong and chess tables, were delivered to more than 50 organizations in Long Island after the show. The project attempts to intervene at an urban scale through the use of basic fixtures. Interboro said: "Holding Pattern operated like an urban design project. The environment we created responded to different desires in ways that a fixed piece of architecture couldn't." 10

\section{PUBLIC DOMESTICITY FOR A SELECTED PUBLIC}

But the programmatic and aesthetic domestication of public space is not unique to design activists. In London's financial center, next to vibrant Liverpool Station, Exchange square, part of the Broadgate complex, hosts screenings of major sports events and selected films during the summer months in an open square fully accessible by the public. These temporary events, fully regulated, result in growing sales for the retail, bars, and restaurants on the perimeter of the square.

At the same time, as the city streets and squares adopt domestic functions, the focus on safety and security comes to the forefront. Everyone's natural desire for a safe environment often results in rising levels of surveillance and economic segregation. Madrid's mayoress, Manuela Carmena, just launched a design competition to design street benches that foster communal outdoor sitting and socialization in order to replace the old 'anti-beggar'ones. The aim has been bringing public space closer to an urban living room. But many people do not want to share their living room with just anyone. The cleaning up and domestication of public space carries with 


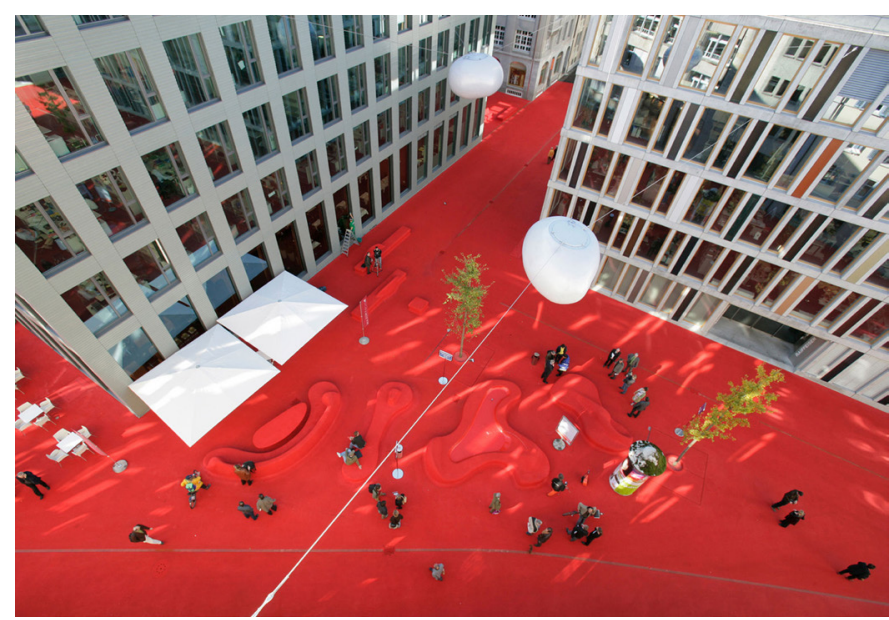

Figure 5: Stadtlounge by Pipilotti Rist and Carlos Martinez, Raiffeisenplatz, St. Gallen, Switzerland, 2005. Photo by Hannes Thalmann. Courtesy of artist Pipilotti Rist and architect Carlos Martinez.

it some disturbing implications regarding exclusion. Questions of selected seclusion from the undesirable and economically heterogenic public mass, have also triggered the interiorization of public functions inside Commercial Plazas and Malls, where privately controlled interior environments provide the means for segregation for a selected public.

The domestication of public environments to provide comfort, familiarity and a homely feeling in outdoor spaces is changing urban practices. Could the semiotics of the domestic eventually disguise the city's streets and squares? If so, interior architects and designers within interdiciplinary teams, could become an asset in the transformation of the city borrowing from models of interior occupation: not streets but corridors, not squares but rooms .

\section{ST. GALLEN'S STADTLOUNGE: MAKE YOURSELF AT HOME}

'Make yourself at home in Switzerland' was the catch phrase used by journalist Samantha Warwik to promote the city of St. Gallen in the Guardian's travel section ${ }^{11}$. Stadtlounge is located in the center of St. Gallen's financial hub, in Switzerland. It was designed by both artist Pipilotti Rist and Carlos Martinez's architectural firm. The designers's ambition was to generate a comfortable outdoor communal living room for St. Gallen. In contrast with the ephemeral nature of most of the previous examples discussed in this paper, this is a permanent intervention. Completed since 2005, Stadtlounge is divided into various areas: a café (with a series of blobby chairs and low-level tables); a relax lounge (with rounded sofas); and a business lounge (with long benches and long tables that can easily host meetings for up to 20 people). At night, a series of giant suspended blobs light up the square.

In this project we can clearly see the semiotics of the domestic altering the physiognomy of the square. The use of the red carpet-like finish, and the organic shaped furniture, generates an atmosphere of softness usually associated with the interior realm. Stadtlounge, recreates certain romantized features of the interior in an exterior environment. The project cristalizes the idealized softness of the living room into a seemingly spongy topography of rigid rubber granulate. The interior-like qualities of the space generate an altered state of perception causing the users to question their relationship to their surroundings and resulting in an exclusive appearance. Its location among banks and insurance buildings, also raises dilemmas about the actual degree of openness of the square at a social level.

\section{CONCLUSION}

The collection of environments and contemporary practices in this article constitute an attempt to grasp the manifold manifestations and implications of the current private-public schism. The contemporary amalgam of public and private entails the progressive transformation of the domestic-versus-public duality, into a singular spatial continuum. The entropic mixture of private and public environments is altering the physiognomy of the city. As program has also become more elastic in the hybridization of these two traditionally contradictory domains, private and public, indoor and outdoor are merged together into a modulated continuum. In Sigfreid Guideon's words, "There is but one indivisible space. The instruments separating inside from outside fall away." 12 While Guideon was referring to the obsolescence of the loadbearing wall and the potential for a fully open architectural perimeter, the increasing indifferentiation between inside an outside, is not just a structural and visual issue anymore, but also semiotic and programmatic. Design within this hybridized environment, relies on the conciliation across its multiple nested scales, on how design is deployed to respond to the recursive relationship between the micro and the macro, between the individual and the collective.

\section{ENDNOTES}

1. Pavon-Cuellar D., "Extimacy" in Encyclopedia of Critical Psychology. Ed. Thomas Teo (New York: Springer, 2014).

2. “Bang (Korean)," Wikepedia, accessed July 26, 2016, https://en.wikipedia.org/wiki/ Bang_(Korean)

3. Carlos Minguez Carrasco, "Ikea disobedients in MoMA PS1", Domus (New York 2012) http://www.domusweb.it/en/architecture/2012/10/03/ikea-disobedientsat-moma-ps1.html 09_Endnotes.

4. Susan Yelavich, "The Interior comes Home" in After Taste, ed. Kent Keinman, Johanna Merwood-Salisbury and Lois Weinthal (New York: Princeton Architectural Press, 2012).

5/6. Ibid

7. Vito Acconci, "Public Space in a Private Time", Critical Inquiry 16 (1990): p.917.

8. "Folly for a Flyover" Assemble's website. Accessed 26 Jul 2016. http://assemblestudio.co.uk/?page_id=5

9. "The Cineroleum / Assemble" Nov 16, 2015. ArchDaily. Accessed 26 Jul 2016. http://www.archdaily.com/777156/the-cineroleum-assemble/

10. "Holding Pattern," Interboro Partners, accessed July 26, 2016, http://www.interboropartners.com/projects/holding-pattern

11. Samantha Warwik, "Make yourself at home," The Guardian, August 6, 2007, accessed July 26, 2016, https://www.theguardian.com/travel/2007/aug/06/switzerland.shortbreaks

12. Sigfreid Giedion, Bauen in Frankreich, Eisen, Eisenbeton (Leipzig: Klinkhardt\&Biermann, 1928), 85, cited in Benjamin, The Arcades Project, 423. 